\title{
Molecular identification and phylogeny of bovine herpesvirus-1 (BoHV-1) from cattle associated with respiratory disorders and death in Turkey
}

\author{
HARUN ALBAYRAK, CUNEYT TAMER, EMRE OZAN*, BAHADIR MUFTUOGLU, \\ HAMZA KADI**, FATIH DOGAN**, AYHAN AKMAN**, ABDURRAHMAN ANIL CAGIRGAN***, \\ AHMED EISA ELHAG, HANNE NUR KURUCAY, SEMRA GUMUSOVA, ZAFER YAZICI \\ Department of Virology, Faculty of Veterinary Medicine, Ondokuz Mayis University, 55139 Samsun, Turkey \\ *Department of Laboratory Animals, Faculty of Veterinary Medicine, Ondokuz Mayis University, 55139 Samsun, Turkey \\ **Samsun Veterinary Control Institute, Ministry of Agriculture and Forestry, 55200 Samsun, Turkey \\ ***Izmir Bornova Veterinary Control Institute, Ministry of Agriculture and Forestry, 35100 Izmir, Turkey
}

Albayrak H., Tamer C., Ozan E., Muftuoglu B., Kadi H., Dogan F., Cagirgan A. A., Elhag A. E., Akman A., Kurucay H. N., Gumusova S., Yazici Z.

Molecular identification and phylogeny of bovine herpesvirus-1 (BoHV-1) from cattle associated with respiratory disorders and death in Turkey

Summary

This study aimed to investigate the presence of bovine herpesvirus 1 by molecular techniques in two cases of respiratory disease in beef cattle, reported from Amasya Province of Turkey in 2018. Nasal swab and lung tissue samples were taken. The presence of bovine herpesvirus-1 (BoHV-1) was confirmed by the PCR method using glycoprotein B (gB) gene-specific primers, and then the isolates were also subjected to partial sequencing. The results of the phylogenetic analysis revealed that the two new isolates in Turkey belonged to the same subclade as subtype 1.1 of $\mathrm{BoHV}-1$, and both also had a $100 \%$ nucleotide (nt) homology with the Cooper reference strain of BoHV-1. These findings can enrich the gB sequence content data for BoHV-1 found in GenBank regarding Turkey.

Keywords: Bovine herpes virus 1, isolate, PCR, sequencing, Turkey

Bovine herpesvirus type-1 (BoHV-1) is an important viral pathogen and the leading cause of multisystemic disorders among large ruminants $(3,16)$. BoHV-1 is an enveloped, double-stranded DNA virus, member of the genus Varicellovirus of the subfamily Alphaherpesvirinae in the family Herpesviridae (10, 18). BoHV-1 causes a variety of clinical manifestations known as infectious bovine rhinotracheitis (IBR), infectious pustular vulvovaginitis (IPV), and infectious balanoposthitis (IBP) in cattle and buffalos (12). BoHV-1 resembles other herpesviruses in its ability to cause a latent infection in which the virus enters neurons after an acute infection and establishes latency by integrating with cellular DNA. The latent virus can be reactivated under appropriate conditions, e.g. stressful factors or application of corticosteroid. Latently infected animals become lifelong virus carriers and can be regarded as a source of BoHV-1 because they shed the virus intermittently (9). BoHV-1 is also one of important pathogens that initiate bovine respiratory disease complex (BRDC) by causing immune suppression that allows secondary infection by bacteria, which leads to respiratory disorders characterized by severe rhinitis, conjunctivitis, pneumonia, and death (3). Furthermore, $\mathrm{BoHV}-1$ is reported as a leading cause of abortions and fetal deaths in some cases. BoHV-1 infection also has a negative impact on the livestock industry because it causes a severe and prolonged decrease in milk yield and the fertility rate (13).

This study is a molecular-based report on the isolation of BoHV-1 strains, newly identified in Turkey, from two heifers suspected of infection by some pathogens of the bovine respiratory disease complex (BRDC). One of them died from respiratory disease, whereas the other showed signs of an illness of the upper respiratory tract. 


\section{Material and methods}

Samples. In December 2018, respiratory disease in two cows was reported from a beef cattle farm located in a rural area of Amasya Province ( $40^{\circ} 49^{\prime} 60^{\prime \prime} \mathrm{N}, 35^{\circ} 39^{\prime} 0$ " $\mathrm{E}$ ) in the Northern Anatolia region of Turkey. One of the two cows showed severe respiratory signs, and the other was dead. A nasal swab was taken from the sick cow and dipped into a sterile tube containing a transport medium with antibiotic solution. Necropsy was performed immediately on the dead cow, and approximately 5 grams of lung tissue was put into a sterile container containing a transport medium with a $2-3 \%$ antibiotic solution. Both specimens were rapidly transported to the laboratory under cold-chain conditions. The swab specimen was vortexed, centrifuged at $1500 \mathrm{rpm}$ for $10 \mathrm{~min}$, and then passed through a $0.22 \mathrm{n \mu}$ filter. Lung tissue was homogenized with Eagle's Minimal Essential Medium (EMEM) (Gibco, Paisley, UK) by means of a tissue lyser (Qiagen, Hilden, Germany) to obtain a 10\% suspension. The nasal swab and tissue samples were enrolled with code numbers TRSAMSUN20194B and TRSAMSUN2019 2B, respectively. All procedures had been approved by the Scientific Research Assessing and Ethical Committee, Ministry of Agriculture and Forestry (decision No. 7/2019, date: 05/07/2019).

DNA extraction. Total DNA extraction from each specimen was performed using commercial extraction kits (Invitrogen, Carlsbad, CA, USA) according to the manufacturer's instructions.

PCR assay. DNA extracted from the swab sample and lung homogenate was subjected to PCR using specific primers (forward 5'-TACGACTCGTTCGCGCTCTC-3' and reverse 5'-GGTACGTCTCCAAGCTGCCC-3') that coded for the glycoprotein $\mathrm{B}(\mathrm{gB})$ gene as previously described by Fuchs et al. (5). PCR was performed in a total of $50 \mu \mathrm{L}$ containing $24 \mu \mathrm{L}$ of nuclease-free water, $5 \mu \mathrm{L}$ of 10XPCR buffer, $5 \mu \mathrm{L}(2.5 \mathrm{mM})$ of $\mathrm{MgCl}_{2}, 2 \mu \mathrm{l}(10 \mathrm{mM})$ of DNTP mix, $2.5 \mu \mathrm{l}$ of DTT, $0.5 \mu \mathrm{l}(5 \mathrm{IU} / \mu \mathrm{l})$ of Taq polymerase, $0.5 \mu \mathrm{l}$ of each primer and $10 \mu \mathrm{L}$ of DNA. PCR was performed under the following amplification conditions: $15 \mathrm{~min}$ at $95^{\circ} \mathrm{C}, 30$ cycles consisting of $30 \mathrm{sec}$ at $95^{\circ} \mathrm{C}$, $30 \mathrm{sec}$ at $56^{\circ} \mathrm{C}, 30 \mathrm{sec}$ at $72^{\circ} \mathrm{C}$ and 1 cycle for $10 \mathrm{~min}$ at $72^{\circ} \mathrm{C}$. Ten microliters of each PCR product was then loaded on a $1.5 \%$ agarose gel stained with ethidium bromide and visualized by the Quantum gel imaging and documentation system (Vilber Lourmat, Collegien, France) running at $100 \mathrm{~V}$ for 40 minutes to detect the 478 base-pair (bp) product for BoHV-1.

Sequencing and phylogenetic analysis. PCR products were purified using a QIAquick PCR purification kit (Qiagen, Hilden, Germany) according to the manufacturer's instructions and then sequenced by RefGen Biotechnology, Ankara, Turkey (http://www.refgen.com). The current sequences were deposited in GenBank with accession numbers MK919465 for TRSAMSUN2019 2B and MK919466 for TRSAMSUN2019 2B.

Assembled consensus sequences of the current isolates were initially aligned using Bioedit, version 7.2.5 followed by BLAST analysis in GenBank databases (7). For comparison, we selected twenty-one representative isolate sequences from GenBank, including not only BoHV-1 strains, but also related herpesvirus strains. The phylogenetic tree was built by the neighbor-joining method operating under Molecular Evolutionary Genetics Analysis (MEGA, version 10.0.2), the boostrap values were based on gB gene nucleotide (nt) sequences, and then tree amino acid sequence was assessed by using 1000 boostrap replications.

\section{Results and discussion}

BoHV-1 DNA was found by the PCR method in both the nasal swab (MK919466) and lung tissue (MK919465) samples, and 478 bp bands corresponding to the $\mathrm{gB}$ gene region of the virus were also visualized by gel electrophoresis (Fig. 1). The BoHV-1 strains were compared with other alphaherpesviruses related to BoHV-1 in terms of percentage similarities and differences in nucleotide (nt) identities. The (nt) sequences of the $\mathrm{gB}$ genes of MK919465 and MK919466 showed $100 \%$ similarity to each other, both being $100 \%$ (nt) similar to field strains from Israel (KF584167), Serbia (MG321246), India (KY215944), China (JN787952), the United States (KU198480, KM258882), and to the vaccine strains MH724205 and MH724208. Furthermore, there was a 99.31\% (nt) identity with BoHV-1(KM258881) from Australia. The nucleotide analysis also showed a 100\% similarity between the current isolates and BoHV-5 (KU992440) from Argentina, while 93.58\% (nt) similarity was determined with BoHV-5 (KY559403) from Brazil.

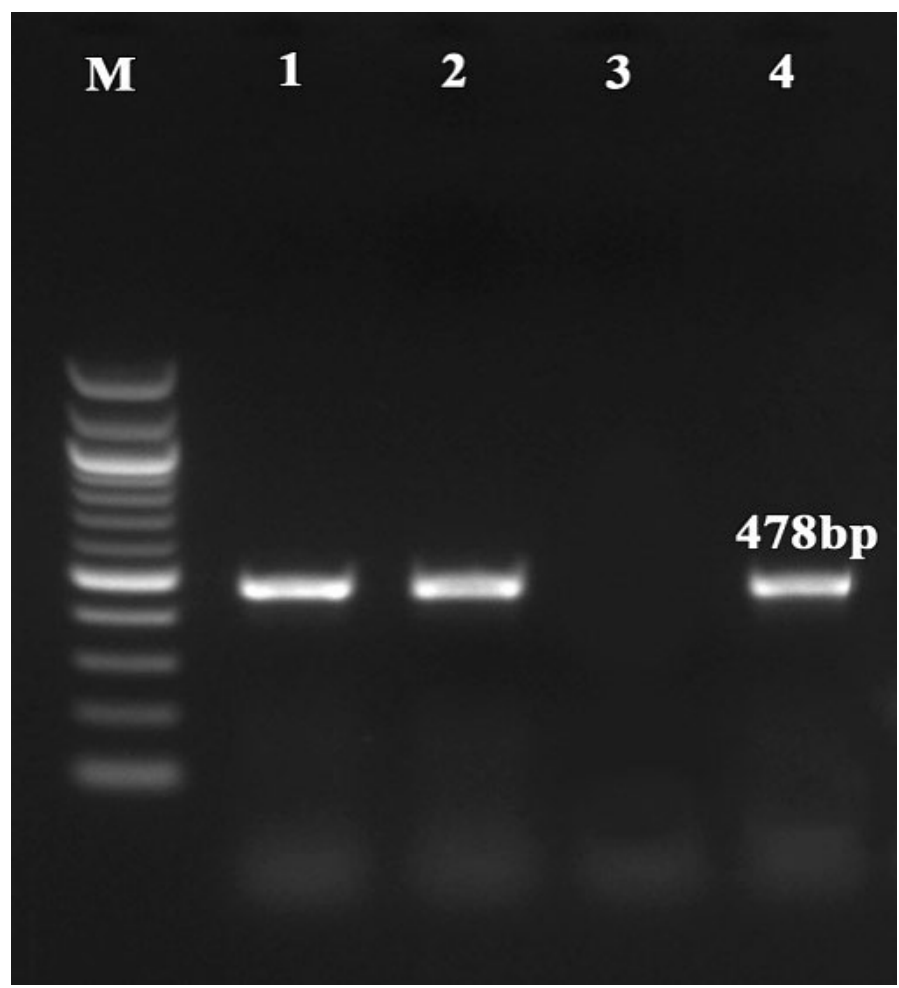

Fig. 1. The results for BoHV-1 in suspected nasal swab and necropsied lung samples

Explanations: Lane M - 100 bp ladder; lane 4 - Cooper strain of BoHV-1 as a positive control corresponding to $478 \mathrm{bp}$; lane 3 - negative control; lane 1 and 2 - MK919465 (lung tissue) and MK919466 (nasal swab) 
Compared separately with bubaline herpesvirus (BuHV-1), cervid herpesvirus (CvHV-1), and caprine herpesvirus (CpHV-1) strains, MK919465 and MK919466 showed (nt) identity ranging from $86 \%$ to $95 \%$. On the other hand, the current isolates showed a $47 \%$ divergence from Suid herpesvirus 1 (SuHV-1) strains NC006151 and KJ717942.

We constructed the phylogenetic tree by the maximum likelihood method, creating both major and minor clusters. The major cluster consisted of bovine herpesvirus 1 and 5 strains, whereas the minor clusters included cervid, caprine, bubaline and suid herpesviruses (Fig. 2). The phylogenetic comparison of MK919465 and MK919466 with ruminant alphaherpesviruses revealed that they were subtype 1.1 and branched with BoHV-1 strains isolated from Israel, Serbia, India, China, the United States, and with the BoHV-5 strain from Argentina. Furthermore, MK919465 and MK919466 also branched with some ruminant alphaherpesviruses in minor clusters with a high degree of nt similarity amounting to $95.31 \%$ for BuHV-1 and varying from $90.12 \%$ to $94.07 \%$ for CvHV-1.

BoHV-1 is the most common virus among eight herpesviruses that are known for their ability to infect cattle naturally (9). Even though BoHV-1 has been eradicated in some European countries, it is common worldwide under the name of IBR/IPV, with a variety of clinical manifestations that may include respiratory and genital diseases, as well as abortions (15). Assessment of the prevalence of IBR/IPV in many parts of the world revealed significant differences in herd-level disease incidence depending on geographical location and cattle management (9). These infections result in huge economic losses in the livestock industry, which may seriously endanger the worldwide animal trade (13). In earlier studies, many researchers report that there is a direct link between the purchasing of new animals and the spreading of the virus among herds (13). The intromission of imported cattle into the country and local herds could be one of the main factors for the entrance of BoHV-1 into Turkey $(6,13)$. Turkey imports cattle from more than fifteen countries in three continents (1). Considering that these countries are not free from IBR and do not have eradication programs, there is an anticipated risk of a new outbreak in the livestock industry in Turkey because of intensive cattle trade with the aforementioned countries combined with the lack of a monitoring program for BoHV-1 at the moment.

In the last few years, many outbreaks caused by some viruses of BRDC have frequently occurred on cattle farms in the Northern Anatolia region of Turkey (17). In the present study, we identified BoHV-1 in two beef cows with respiratory disorders from a small farm by $\mathrm{PCR}$ targeting the $\mathrm{gB}$ gene of the virus. The $\mathrm{gB}$ is one of the major envelope proteins of herpesviruses, which is responsible for virus penetration and entry $(8,14)$. Molecular diagnosis and sequencing of the $\mathrm{gB}$ gene is one of the methods frequently used by many researchers to understand the epidemiology and distribution of BoHV-1 worldwide (11). In the present study, both MK919465 and MK919466 were confirmed as BoHV-1, and a 100\% nucleotide homology was determined between them by partial sequence analysis. Compared with the reference field and vaccine strains of BoHV-1 in GenBank, nucleotide similarity of both MK919465 and MK919466 ranged between 99\% and 100\%. Aligned (nt) sequences revealed a high degree of similarity with ruminant alphaherpesviruses in the present study: $95.31 \%$ for BuHV-1, from $93.58 \%$ to $100 \%$ for BoHV-5, and from $90.12 \%$ to $94.07 \%$ for CvHV-1. Furthermore, an $86 \%$ nucleotide homology was determined between the current isolates and $\mathrm{CpHV}-1$, which was lower than for the other alphaherpesviruses. This seems to be an interesting result because $\mathrm{CpHV}-1$ is thought to play a role in the transmission of BoHV-1 
as well as having a close antigenic relationship with BoHV-1.

The phylogenetic analysis revealed that our isolates, MK919465 and MK919466, were in the same cluster with subtype 1.1 of BoHV.1, corresponding to the $\mathrm{gB}$ gene nucleotide sequences of BoHV-1 obtained from the field strain that includes the reference Cooper strain and vaccine strains. Subtype 1.1 usually comprises strains responsible for respiratory disease (15). This result is unsurprising, since the current isolates, MK919465 and MK919466, had been detected in cattle with severe respiratory signs.

Another important finding of the present study is that our isolates belonged to the same cluster as a BoHV-5 isolate from Argentina (KU992440) and to a branch close to a BoHV-5 isolate from Brazil (KY559403). In earlier studies, BoHV-1 and BoHV-5 were reported to share at least an $85 \%$ antigenic similarity (4), and, to our knowledge, no reports on the isolation and identification of BoHV-5 are available in Turkey, although there are some serological studies. This finding is also relevant to the hypothesis that BoHV-5 is in circulation in the Amasya region in addition to the BoHV-1. Furthermore, our isolates were also located on a branch close to BuHV-1 (KU936049 and MH253680) and CvHV-1 (AF078729 and MH036942). This could be a result of the fact that the primers used for detection of BoHV-1 were designed for the $\mathrm{gB}$ gene region, which is well known as the most conserved glycoprotein (14).

In conclusion, our findings can contribute to two important points. (i) A total of fourteen partial sequence reports were found by screening BoHV-1 records for Turkey in GenBank. Thirteen of these sequences were obtained by targeting the $\mathrm{gC}$ gene region of the virus, and only one sequence, submitted by Aslan et al. (2), was acquired by targeting the gB-gene region. Hence the submission of $\mathrm{gB}$ sequence data obtained from the current study could enrich the $\mathrm{gB}$ sequence content of BoHV-1, and could also represent a contribution to the limited BoHV-1 data in GenBank regarding Turkey. (ii) In this study, we reported the identification and partial genome sequencing of two BoHV-1 isolates that could circulate in Turkey. Detailed investigations are needed for a better understanding of the dynamics of BoHV-1 and related viruses, which may have a positive impact on developing the livestock industry in Turkey. In this context, we recommend that further comprehensive studies of the current situation of IBR in Turkey be planned in order to develop an effective eradication and control program for Turkish livestock.

\section{References}

1. AlbayrakH., Yazici Z., Ozan E., Tamer C., El Wahed A. A., Wehner S., Ulrich K., Weidmann M.: Characterisation of a first bovine parainfluenza virus 3 isolate detected in cattle in Turkey. Vet. Sci. 2019, 6, 56.

2. Aslan M. E., Azkur A. K., Gazyagci S.: Epidemiology and genetic characterization of BVDV, BHV-1, BHV-4, BHV-5 and Brucella spp. infections in cattle in Turkey. J. Vet. Med. Sci. 2015, 77, 1371-1377.
3. Biswas S., Bandyopadhyay S., Dimri U., Patra P. H.: Bovine herpesvirus-1 (BHV-1) a re-emerging concern in livestock: a revisit to its biology, epidemiology, diagnosis, and prophylaxis. Vet. Q. 2013, 33, 68-81.

4.Delhon G., Moraes M. P., Lu Z., Afonso C. L., Flores E. F., Weiblen R., Kutish G. F., Rock D. L.: Genome of bovine herpesvirus 5. J. Virol. 2003, 77, 10339$-10347$.

5. Fuchs M., Hubert P., Detterer J., Rziha H. J.: Detection of Bovine Herpesvirus Type 1 in Blood from Naturally Infected Cattle by Using a Sensitive PCR That Discriminates between Wild-Type Virus and Virus Lacking Glycoprotein. E. J. Clin. Microbiol. 1999, 37, 2498-2507.

6. Gungor A. B., Ozkul A.: Dynamics of natural bovine herpesvirus-1 (BoHV-1) infection in a dairy herd. Trop. Anim. Health Prod. 2007, 39, 13-20.

7. Hall T.: BioEdit: a user-friendly biological sequence alignment editor and analysis program for Windows 95/98/NT. Nucleic Acids Symp. Ser. 1999, 41, 95-98.

8.Levings R. L., Collins J. K., Patterson P. A., Roth J. A.: Virus, strain, and epitope specificities of neutralizing bovine monoclonal antibodies to bovine herpesvirus 1 glycoproteins $\mathrm{gB}, \mathrm{gC}$, and $\mathrm{gD}$, with sequence and molecular model analysis. Vet. Immunol. Immunopathol. 2015, 164, 179-193.

9. Nettleton P., Russell G.: Update on infectious bovine rhinotracheitis. In Practice 2017, 39, 255-272.

10. OIE. Infectious bovine rhinotracheitis/infectious pustular vulvovaginitis, [in:] Manual of standards for diagnostic tests and vaccines for terrestrial animals. 2018, Chapter 3.4.11, p: 1139-1157 [Version adopted 2017 May]. Available from: https:/www.oie.int/fileadmin/Home/eng/Health_standards/ tahm/3.04.11 IBR IPV.pdf.

11. Patil S. S., Prajapati A., Hemadri D., Suresh K. P., Desai G. S., Reddy G. B. M., Chandranaik B. M., Ranganatha S., Rahman H.: Phylogenetic analysis of glycoprotein B gene sequences of bovine herpesvirus 1 isolates from India reveals the predominance of subtype 1.1. Vet. World 2016, 9, 1364-1369.

12. Rana S. K., Kota S. N. L. S., Narasimha P., Samayan R., Rajan S., Sirinivasan $V$. A.: Use of real time polymerase chain reaction to detect bovine herpes virus 1 in frozen cattle and buffalo semen in India. Vet. Ital. 2011, 47, 313-322.

13. Rola J., Larska M., Polak M. P.: The detection of Bovine herpesvirus 1 from an outbreak of infectious bovine rhinotracheitis. Bull. Vet. Inst. Pulawy 2005, 49, 267-271.

14. Sobhy N. M., Mor S. K., Mohammed M. E. M., Bastawecy I. M., Fakhry H. M., Youssef C. R. B., Goyal M. G.: Comparative molecular characterization of bovine herpesvirus-1 strains from Egypt and the United States. Life Sci. J. 2014, 11, 493-499.

15. Traesel C. K., e Silva M. S., Spilki F. R., Weiblen R., Flores E. F.: Nucleotide sequencing and phylogenetic analysis of the 3 ' region of glycoprotein $\mathrm{C}$ gene of South American bovine herpesviruses 1 and 5. Res. Vet. Sci. 2013, 94, 178-185

16. Yazici Z., Albayrak H., Ozan E., Gumusova S.: Serological status of bovine herpes virus type 1 in cattle in small scale private farms in the Central Black Sea Region, Turkey. Pak. Vet. J. 2015, 35, 101-102.

17. Yazici Z., Gumusova S., Tamer C., Muftuoglu B., Ozan E., Arslan S., Bas O., Elhag A. E., Albayrak H.: The first serological report for genotype C bovine parainfluenza 3 virus in ruminant species of mid-northen Turkey: Traces from the past. Trop. Biomed. 2019, 36, 803-809.

18. Zhu L., Yu Y., Jiang X., Yuan W., Zhu G.: First report of bovine herpesvirus 1 isolation from bull semen samples in China. Acta Virol. 2017, 61, 483-486.

Corresponding author: Prof. Zafer Yazici DVM, MVSc, PhD, Department of Virology, Faculty of Veterinary Medicine, Ondokuz Mayis University, Kurupelit Campus, 55139 Atakum, Samsun, Turkey; e-mail: zyazici@ omu.edu.tr 